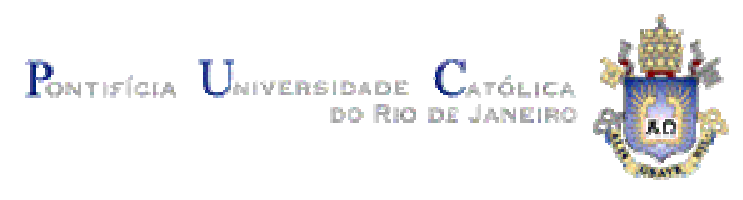

Nathalia Ferreira Masson

\title{
O CONCEITO DE SANÇÃO NA TEORIA ANALÍTICA DO DIREITO
}

Orientador: Adrian Sgarbi

Dissertação apresentada ao Programa de PósGraduação em Direito da PUC-Rio como requisito parcial para a obtenção do título de Mestre em Direito. 


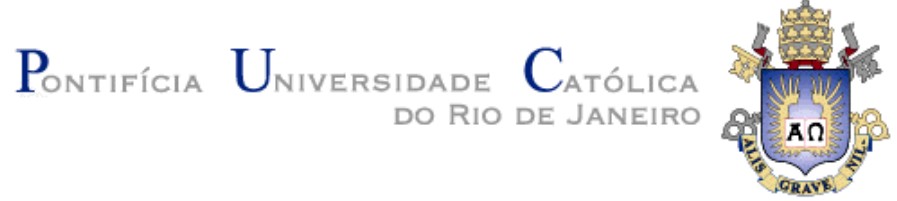

Nathalia Ferreira Masson

\title{
O CONCEITO DE SANÇÃO NA TEORIA ANALÍTICA DO DIREITO
}

Dissertação apresentada ao Programa de Pósgraduação em Direito do Departamento de Direito da PUC-Rio como parte dos requisitos parciais para a obtenção do título de Mestre em Direito.

\author{
Prof. Adrian Sgarbi \\ Orientador \\ Departamento de Direito - PUC-Rio \\ Prof. Alejandro Bugallo Alvarez \\ Departamento de Direito - PUC-Rio \\ Prof. Noel Struchiner \\ Departamento de Filosofia - UFRJ
}

Prof. João Pontes Nogueira Vice-Decano de Pós-Graduação do Centro de Ciências Sociais - PUC-Rio

Rio de Janeiro, 15 de junho de 2007. 
Todos os direitos reservados. É proibida a reprodução total ou parcial do trabalho sem autorização da universidade, do autor e do orientador.

\section{Nathalia Ferreira Masson}

possui graduação em Direito pela Universidade Federal de Juiz de Fora em 2004.

Ficha catalográfica

Masson, Nathalia Ferreira

O Conceito de Sanção na Teoria Analítica do Direito / Masson, Nathalia Ferreira; orientador: Adrian Sgarbi. - Rio de Janeiro: PUC, Departamento de Direito, 2007.

viii.; 153f.:il.: 29,7 cm

1. Dissertação (mestrado) - Pontifícia Universidade Católica do Rio de Janeiro, Departamento de Direito.

Inclui referências bibliográficas.

1. Direito - Teses. 2. Sanção. 3. Jeremy Bentham; 4. John Austin. 5. Hans Kelsen. 6. Teoria Analítica do Direito. I. Sgarbi, Adrian. II. Pontifícia Universidade Católica do Rio de Janeiro. Departamento de Direito. III. Título. 


\section{Agradecimentos}

"Uma pesquisa sem agradecimentos é suspeita."

Umberto Eco

Ao meu orientador, professor Adrian Sgarbi, por todo seu brilhantismo acadêmico e orientações valiosas dadas com sincera afeição.

Aos demais professores do Programa de Pós-Graduação em Direito da PUC-Rio, por todas as excelentes aulas ministradas.

Ao Anderson e à Carmen, pelo trato sempre amistoso e compreensivo e a indiscutível presteza em solucionar todas as minhas dificuldades administrativas.

À PUC-Rio e à CAPES, pelo indispensável auxílio financeiro.

A todos os amigos que partilharam idéias e fomentaram discussões, auxiliando na construção desse trabalho.

Aos meus queridos pais, por todo incentivo e amor.

Ao Victor e ao Renan, eternos amigos, pela alegre companhia e por todo o carinho e cumplicidade.

Ao Hugo, por me fazer tão feliz. 


\section{Resumo}

Masson, Nathalia Ferreira; Sgarbi, Adrian. O conceito de sanção na teoria analítica do direito. Rio de Janeiro, 2007. 153p. Dissertação de Mestrado - Departamento de Direito, Pontifícia Universidade Católica do Rio de Janeiro.

A presente dissertação diz respeito a um dos temas centrais da Teoria do Direito: o conceito de sanção. Muitos dos conceitos jurídicos básicos - inclusive o próprio conceito de Direito - encontram-se estritamente conectados com ele, de forma que um estudo cuidadoso sobre esse tema possibilitará que muitas outras questões fundamentais do Direito sejam, senão resolvidas, ao menos aclaradas. As inúmeras subdivisões que a complexidade do tema acarreta tornaram necessárias delimitações quanto ao objeto de estudo. Portanto, dentro da ampla esfera interessante ao pesquisador empenhado em deslindar o tema, optou-se por centrar a pesquisa em objetivos mais modestos: o de reconhecer e apresentar os principais problemas que encerram o conceito de sanção para a teoria do direito em três autores específicos - Jeremy Bentham, John Austin e Hans Kelsen - pertencentes a uma mesma tradição de pensamento jurídico, a Teoria Analítica do Direito (analytical jurisprudence). Tal escolha é facilmente justificável, em virtude da centralidade do conceito em suas concepções de Direito.

\section{Palavras-chave}

Sanção, Jeremy Bentham, John Austin, Hans Kelsen, Teoria Analítica do Direito. 


\section{Abstract}

Masson, Nathalia Ferreira; Sgarbi, Adrian. The concept of sanction in the Analytical Jurisprudence. Rio de Janeiro, 2007. 153p. Dissertação de Mestrado - Departamento de Direito, Pontifícia Universidade Católica do Rio de Janeiro.

The present work refers to one of the central subjects of the Legal Theory: the concept of sanction. Many of the basic legal concepts - and the concept of Law itself - are strictly connected with it, in such a way that a careful study on this subject will make possible that many other basic questions of the Law are, if not solved, at least clarified. Because of the innumerable subdivisions caused by that the complexity of the subject, it had become necessary to delimitate the studied object. Therefore, within the wide area of interest presented by the subject, the researcher has opted to focus his/her work on more modest objectives: to recognize and to present the main problems concerning the concept of sanction inside the work of three specific authors - Jeremy Bentham, John Austin and Hans Kelsen -, being them all part of the same legal thought tradition, the analytical school of jurisprudence. Such choice is justified by the unquestionable importance that the authors confer to the sanctions in their legal theories.

\section{Keywords}

Sanction, Jeremy Bentham, John Austin, Hans Kelsen, Analytical School of Jurisprudence. 


\section{Sumário}

$\begin{array}{ll}\text { 1. Introdução } & 10\end{array}$

2. Thomas Hobbes e o Senhor das Moscas 23

3. O conceito de sanção em Jeremy Bentham 24

3.1. Introdução $\quad 24$

3.2. Apontamentos biográficos 25

3.3. Alguns pressupostos da teoria do direito de Bentham 26

3.3.1. Os deveres e a teoria probabilística 29

3.4 Jeremy Bentham e as sanções 31

3.4.1. Introdução 31

3.4.2 Aspectos estruturais das sanções em Bentham 31

3.4.3 A individualização das normas jurídicas 33

3.4.4 Aspectos funcionais das sanções em Bentham 36

3.5 As recompensas em Bentham 39

3.6 Críticas ao modelo benthaniano 40

4. O conceito de sanção em John Austin 42

4.1 Introdução 42

4.2 Breves apontamentos biográficos 44

4.3 A teoria de John Austin. Alguma arquitetura. $\quad 45$

4.3.1 Apresentação sistemática da obra "A Delimitação do Objeto do Direito" 45

4.3.2 Austin e o Soberano 47

4.3.2.1 Hobbes e o soberano supremo $\quad 47$

4.3.2.2. Bentham e o soberano utilitário 49

4.3.2.3 A construção do conceito em Austin 51

4.3 O objeto de estudo do Direito 55

4.4 John Austin e as sanções $\quad 59$

4.4.1 Introdução $\quad 59$

4.4.2 A inafastável correlação dos termos comando, dever e sanção 60

4.4.3 A estrutura das sanções $\quad 64$

4.4.3.1 O Dano 65

$\begin{array}{ll}\text { 4.4.3.2 A probabilidade } & 66\end{array}$

$\begin{array}{ll}\text { 4.4.3.3 A desobediência } & 66\end{array}$

$\begin{array}{ll}\text { 4.4.3.4 A ameaça } & 68\end{array}$

$\begin{array}{ll}\text { 4.4.3.5 A eventualidade } & 69\end{array}$

4.4.4 A funcionalidade das sanções: motivos para obediência 69

4.4.4.1 Efeito direto: o encorajamento à obediência 70

4.4.4.2 Efeito indireto - ou como se forma um hábito de obediência? 73

4.4.4.3 O conceito extraordinariamente amplo de sanção e sua

primordial conseqüência: a caracterização das nulidades como sanção $\quad 74$

4.5 Sanções civis, sanções criminais $\quad 76$

$\begin{array}{ll}4.6 \text { Críticas ao modelo austiniano } & 78\end{array}$

$\begin{array}{ll}\text { 4.6.1 Introdução } & 78\end{array}$

4.6.2 Concepção homogênea das normas: a sanção como critério
individualizador dos ordenamentos jurídicos

4.6.3 Nulidades como sanções: redenção do modelo austiniano? 81

4.6.4 O encadeamento de sanções e o inevitável regresso ao infinito 83

4.6.5 A diferença entre 'se ver obrigado' e 'ter uma obrigação' como crítica

à teoria imperativista do direito 
5. O conceito de sanção em Hans Kelsen 88

5.1 Introdução $\quad 88$

5.2 Breves apontamentos biográficos $\quad 91$

5.3 Considerações sobre a teoria jurídica de Hans Kelsen: uma abordagem da Teoria Pura

$\begin{array}{ll}5.4 \text { Hans Kelsen e as sanções } & 106\end{array}$

$\begin{array}{ll}\text { 5.4.1 Introdução } & 106\end{array}$

5.4.2 Delimitando o conceito de sanção 108

$\begin{array}{ll}\text { 5.4.2.1 Ato coativo } & 108\end{array}$

5.4.2.2 Sanção como conseqüência de uma conduta 109

5.4.2.3 A sanção como um mal 111

5.4.2.4 A autorização para aplicar a sanção e a validade das normas 112

5.4.3 Sentido amplo e sentido amplíssimo das sanções 115

5.4.4 Outras possíveis classificações para as sanções na obra de Kelsen 117

5.4.4.1 Sanções transcendentais e socialmente imanentes 117

$\begin{array}{ll}\text { 5.4.4.2 Sanções civis e penais } & 119\end{array}$

$\begin{array}{ll}\text { 5.4.4.3 As sanções no Direito Internacional } & 121\end{array}$

$\begin{array}{ll}\text { 5.4.4.3.1 Considerações introdutórias } & 121\end{array}$

5.4.4.3.2 O ilícito e a sanção no Direito Internacional 122

5.4.4.3.3 A teoria do bellum justum como critério de reconhecimento do

Direito Internacional como Direito 126

5.4.5 A sanção enquanto conceito primário da teoria do direito de Kelsen $\quad 128$

$\begin{array}{ll}\text { 5.4.5.1 Introdução } & 128\end{array}$

5.4.5.2 Individualização das disposições jurídicas através da sanção 129

5.4.5.3 A definição de outros conceitos a partir da sanção 132

5.4.5.3.1 O ilícito gera a sanção ou a sanção gera o ilícito? 132

$\begin{array}{ll}\text { 5.4.5.3.2 A sanção e as obrigações jurídicas } & 135\end{array}$

$\begin{array}{ll}\text { 5.4.5.3.3 A sanção e a responsabilidade } & 137\end{array}$

5.4.5.3.4 A sanção e os direitos subjetivos 139

$\begin{array}{ll}\text { 5.4.6 Críticas ao modelo kelseniano } & 143\end{array}$

$\begin{array}{ll}\text { 5.4.6.1 Introdução } & 143\end{array}$

5.4.6.2 A redução do Direito à Força 144

$\begin{array}{lr}\text { 6. Conclusão } & 147\end{array}$

7. Referências Bibliográficas 152 
“... sobre o problema da sanção foram derramados rios de tinta pelos clássicos: quase se poderia distinguir os filósofos do direito do passado e do presente em duas grandes fileiras, das quais uma é aquela dos 'sancionistas' e a outra a dos 'não-sancionistas'. Talvez não haja problema da filosofia do direito que tenha atraído maiores e mais ferozes discussões, e que tenha sido objeto de maiores indagações e reflexões. (Norberto Bobbio, Teoria da Norma Jurídica). 